\title{
Vaccination nursing records: importance for monitoring the health of populations
}

Registos vacinais de enfermagem: importância para vigilância da saúde das populaçôes Registros de vacunación de enfermería: importancia para el control de la salud de la población

João Manuel Graça Frade* (D); Carolina Miguel Graça Henriques** (D); Fátima Frade*** (D)

\begin{abstract}
Background: Vaccination nursing records are a source of relevant information for adequate epidemiological surveillance of the implementation of the National Vaccination Program.

Objectives: To evaluate the reliability and accuracy of vaccination nursing records related to the measles-mumps-rubella vaccination strategy (MMR).

Methodology: The official vaccination records of 411 individuals, born between 1970 and 2004, were examined. We studied their vaccination, disease, and vaccination adverse reactions history.

Results: There is a coincidence of vaccination information recorded in the Individual Vaccination Record and the Individual Health card in $96.22 \%$. The followed vaccination schedules were associated with the birth generations to which individuals belong $(r=0.720 ; p=0.020)$. Vaccination status was not associated with either the history of disease or the history of adverse reactions to vaccination $(p>0.05)$.

Conclusion: Vaccination nursing records are reliable and accurate, allow the monitoring and surveillance of the health of populations, and ensure the success of the implementation of the National Vaccination Program in Portugal.
\end{abstract}

Keywords: vaccination; nursing; health status indicators; public health

\section{Resumo}

Enquadramento: Os registos vacinais de enfermagem são uma fonte de informaçáo relevante para uma adequada vigilância epidemiológica da aplicação do Programa Nacional de Vacinação.

Objetivos: Avaliar a fiabilidade e precisão dos registos vacinais de enfermagem relativos à estratégia vacina antissarampo, parotidite e rubéola (VASPR).

Metodologia: Foram consultados os registos oficiais de vacinação de 411 indivíduos, nascidos entre 1970 e 2004. Através destes registos estudou-se a história vacinal, de doença e de reaçóes adversas à vacinação.

Resultados: Existe informação vacinal coincidente registada na ficha individual de vacinação e no boletim individual de saúde em 96,22\%. Os esquemas vacinais seguidos estiveram associados a geraçóes de nascimento às quais os indivíduos pertencem $(r=0,720 ; p=0,020)$. $\mathrm{O}$ estado vacinal não esteve associado nem à história de doença nem à história de reaçóes adversas à vacinação $(p>0,05)$.

Conclusáo: Os registos vacinais de enfermagem são fiáveis e precisos, permitem a monitorizaçáo e vigilância da saúde das populaçóes e garantem o sucesso da aplicação do Programa Nacional de Vacinação em Portugal.

Palavras-chave: vacinação; enfermagem; indicadores básicos de saúde; saúde pública

*Ph.D., Adjunct Professor, Health School, Polytechnic Institute of Leiria, 2411-901, Leiria, Portugal [joao.frade@ipleiria.pt]. D https://orcid.org/0000-0002-4947-1052.Contribution in the article: research and writing of the article. Address for correspondence: Campus 2 - Morro do Lena - Alto do Vieiro, Apartado 4137, 2411-901, Leiria, Portugal.

**Ph.D., Post-Doc, Adjunct Professor, Health School, Polvtechnic Institute of Leiria, 2411-901, Leiria, Portugal [carolina.henriques@ipleiria.pt]. (1) https://orcid.org/0000-0002-0904-8057. Contribution to the article: research and writing of the article.

****Ph.D., Adjunct Professor, Health School, Atlântica, 2730-036, Oeiras, Portugal [ffrade@ uatlantica.pt]. (1) https://orcid.org/0000-0002-6190-5298. Contribution to the article: research and writing of the article.

\section{Resumen}

Marco contextual: Los registros de vacunación de enfermería son una fuente de información pertinente para realizar un control epidemiológico adecuado de la aplicación del Programa Nacional de Vacunación.

Objetivos: Evaluar la fiabilidad y la precisión de los registros de vacunación de enfermería relativos a la estrategia de vacunación contra el sarampión, la parotiditis y la rubeola (VASPR).

Metodología: Se consultaron los registros oficiales de vacunación de 411 individuos nacidos entre 1970 y 2004. A través de estos registros, se estudió el historial de vacunación, de enfermedad y de reacciones adversas a la vacunación.

Resultados: Existe información de vacunación coincidente registrada en la cartilla de vacunación individual y en el boletín individual de salud al 96,22\%. Los esquemas de vacunación seguidos se asociaron con generaciones de nacimiento a las cuales pertenecen los individuos $(r=0,720 ; p=0,020)$. El estado de vacunación no se asoció ni con el historial de enfermedad ni con el historial de reacciones adversas a la vacunación $(p>0,05)$. Conclusión: Los registros de vacunación de enfermería son fiables y precisos, permiten el seguimiento y el control de la salud de las poblaciones y garantizan el éxito de la aplicación del Programa Nacional de Vacunación en Portugal.

Palabras clave: vacunación; enfermería; indicadores de salud; salud pública 


\section{Introduction}

Within the context of the National Vaccination Program (NVP), nurses play an essential role in the production of epidemiological surveillance indicators, relevant to the successful implementation of this program in Portugal, in addition to the technical skills related to vaccine administration and all other operations associated with the act of vaccinating. These indicators can be extracted from the vaccination records in the Individual Health Card (BIS) and the Individual Vaccination Record (FIV), which is now computerized in the Primary Health Care National Information System (SINUS) in Portugal. In other words, nursing interventions in this area of clinical practice are not limited to individual care to people who vaccinate. They do have a more important purpose, which is the production of indicators that allow the monitoring and surveillance of the health of populations while contributing to the evaluation of successful strategies used to modify the course of health/disease processes.

In this study, we aim to demonstrate the reliability and accuracy of clinical nursing records related to the studied sample, allowing to reflect the nursing practice in Portugal in the vaccination field. We also show that these records are a good source of data for the epidemiological surveillance of the NVP implementation, namely as regards the vaccination coverage data, for the quality of vaccination information registered in the BIS and the FIV, and for the study of their possible relationship with the history of the disease and/or adverse reactions to vaccination. This is exemplified by the application of the combined measles-mumps-rubella vaccine (MMR) strategy due to the occurrence of recent cases of measles in Portugal.

\section{Background}

The nursing intervention is perceived as the autonomous action of the nurse (Loureiro, 2004; Witt, 2013), based on his/her scientific knowledge and skills, with the purpose of benefitting the patient, the families, and the community, within a nursing process that reflects the results of this intervention. In the area of vaccination, we can divide the nursing care in three distinct moments: pre-vaccination, vaccination, and post-vaccination. At the moment of post-vaccination, nurses should make records of the administered vaccines, including the details about the name and formulation of the administered vaccine, the dose and the dose number of the vaccine applied, the batch number, and the date of inoculation, as well as the adverse reactions to previous vaccinations. These records must be made in at least two documents: the FIV and the BIS (Direção-Geral da Saúde, 2017; Frade, Frade, Henriques, Silva, \& Gonçalves, 2017; Loureiro, 2004; Witt, 2013; Subtil, 2011).

The evaluation of the quality of the vaccination information related to a particular vaccination strategy lacks the knowledge of the norms and guidelines associated with the implementation of this strategy (Direção-Geral da Saúde, 2017; Frade et al., 2017). This research studies the quality of vaccination information concerning the MMR vaccination strategy, so it is essential to know the evolution of the application of this strategy in the national territory.

The measles vaccine (VAS) was implemented in Portugal in 1973. From this year onward, due to different changes of the NVP relating to this strategy, we can identify three distinct vaccination generations and their corresponding vaccination schedules in Portugal (Direção-Geral da Saúde, 2017; Frade et al., 2017). The first generation was born before 1977 , only had the opportunity to receive one dose of measles vaccine, and followed the VAS I schedule. The second generation was born between 1977-1984, had the opportunity to receive two vaccine doses, and followed the VAS I and VAS II/MMR1 schedule. The third generation was born after 1984, had the opportunity also to receive two vaccine doses (as the first could already be administered through the MMR formulation, and followed the MMR1 and MMR2 schedule. We can find the sole MMR1 schedule in the generation born between 1877-1985, in individuals who were vaccinated only after the age recommended by the Directorate-General for Health (DGS), and in the generation born after 1984, if they did not complete vaccination with the MMR2 (Frade et al., 2017). The knowledge of vaccination schedules, followed of the vaccination coverage rate, of the administration dates of vaccines, and of vaccine formulations received, has great epidemiological relevance to determining 
the immunological profile and also to the establishment of possible relations between the history of disease and adverse reactions to vaccination (George et al., 2017; Gonçalves, Frade, Nascimento, Mesquita, \& Nunes, 2016; Gonçalves, Frade, Nunes, Mesquita, \& Nascimento, 2015). As regards the occurrence of disease, there are no recorded cases of the endemic disease in Portugal since 2004, although several cases of measles have occurred from 2011 onwards, in various European countries. In the last 2 years, Portugal also registered significant outbreaks, although cases have been considered to be imported (European Centre for Disease Prevention and Control, 2011; European Centre for Disease Prevention and Control, 2017; European Centre for Disease Prevention and Control, 2019).

The occurrence of recent disease cases in Portugal may be related to the weakened immune profile of the Portuguese population. This fact could question the phenomenon of group immunity and the possible appearance of disease (Gonçalves et al., 2015). Regarding adverse reactions to vaccination, their number is small and little incident, as the vaccine is very safe and effective (Cutts, Lessler, \& Metcal, 2013).

\section{Research Questions}

Are the vaccination records of nursing that allow performing epidemiological surveillance of the NVP implementation, namely the MMR vaccination strategy, reliable and valid?

Were the vaccines administered according to the guidelines of the Directorate-General for Health at the time, in order to obtain high vaccination coverage rates?

Do the vaccination records correspond to the vaccine formulations available at the time? Is the information recorded in the BIS identical to that recorded in the FIV?

Are the reports of the history of disease and adverse reactions to vaccination in compliance with the vaccination information recorded in the BIS and FIV?

\section{Methodology}

A cross-sectional study was carried out to 411 patients born between 1970 and 2004, belong- ing to the Health Center Cluster of Pinhal Litoral (ACES Pinhal Litoral) and the Local Health Unit (ULS) of Guarda, Portugal. We studied the history of MMR vaccination, measles, and adverse reactions to MMR vaccination. The data for this study were obtained in nursing consultations through a small questionnaire, which the nurse applied using the structured interview. Patients were asked about antecedents of their clinical history and the possible existence of adverse reactions to vaccination. Subsequently, data were collected through the consultation of the FIV, vaccination files, and data on the MMR vaccination strategy, between 2012 and 2014, in a convenience sample. Hence, the questionnaire was applied by interviewing 411 patients, conducted by the nurse in the nursing consultation. Only the individuals with vaccination history recorded in the BIS and FIV, registered in the corresponding health units, were included in the study. At the time of the interview, those who did not provide the BIS were asked to send us a copy by post in pre-paid envelopes.

We entered the data from the vaccination history and the interviews in a database, where they were treated using the IBM SPSS Statistics program, version 23.0 (SPSS Inc., Chicago, Illinois).

The main independent variables studied were the vaccination schedule and year of birth. The confidence intervals were defined at $95 \%$. The association degree of the different variables was measured through Phi and Cramer's V. We even used the chi-squared test of independence. As regards ethical issues, this study was approved by the Coordination of the Public Health Unit of ACES Pinhal Litoral and by the Ethics Committee of the ULS Guarda. All individuals included in the study signed a free and informed consent form. The data analysis maintained the rules of confidentiality and anonymity of the studied individuals, without any possibility of identification.

\section{Results}

Concerning the coincident vaccination information recorded in the FIV and BIS, we can note that, of the 411 individuals included in the sample, we obtained the FIV of 318 indi- 
viduals $(73.77 \%)$ and the BIS of 252 individuals $(63.13 \%)$. In the case of 159 individuals $(38.68 \%)$, we obtained the two documents and were able to compare the information recorded in both, regarding the registered vaccine formulation and the vaccination date. In only six individuals, the information of the two documents did not coincide (3.77\%). That was because the FIV of five individuals lacked the registration and in one case only there was a mismatched date of registration of the vaccine (Table 1).

Table 1

Coincident vaccination information recorded in the BIS and FIV

\begin{tabular}{ccccc}
\hline & & \multicolumn{2}{c}{ Vaccination information in the BIS = FIV } & \multirow{2}{*}{ Total } \\
\cline { 3 - 4 } & \multicolumn{1}{c}{} & Yes & No & \\
\cline { 2 - 3 } Generation of & 1977 & 9 & & 9 \\
birth & $1977-1984$ & 42 & 5 & 47 \\
& $>1985$ & 102 & 1 & 103 \\
& Total & 153 & 6 & 159 \\
\hline
\end{tabular}

Note. BIS = Individual Health Card; FIV = Individual Vaccination Record.

Analyzing the vaccination status (0 VAS; 1 VAS; 2 VAS) of the sample (Table 2), we noted the immunization coverage rate increases from the older generations to the younger generations. The generation born before 1984 presents the highest proportion of individuals with zero doses of vaccine $(51 / 58 ; 87.93 \%)$ and the generation born after 1984 presents the highest number of individuals with two vaccine doses $(237 / 282 ; 84.04 \%)$. The vaccination coverage rate was $0 \%$ in the generation born before 1977 for the two vaccine doses and higher than $90 \%$ in the generation born after 1985 for the same two vaccine doses.

Table 2

Evolution of vaccination status in the studied sample

\begin{tabular}{|c|c|c|c|c|c|c|c|}
\hline \multirow{3}{*}{ Variables } & & \multicolumn{3}{|c|}{ No. of vaccine doses } & \multirow{3}{*}{ Total } & \multirow{2}{*}{\multicolumn{2}{|c|}{$\begin{array}{c}\text { Vaccination coverage rate } \\
(\%)\end{array}$}} \\
\hline & & \multirow{2}{*}{0} & \multirow{2}{*}{1} & \multirow{2}{*}{2} & & & \\
\hline & & & & & & $1^{\text {st }}$ dose & $2^{\text {nd }}$ dose \\
\hline \multirow{4}{*}{$\begin{array}{l}\text { Generation of } \\
\text { birth }\end{array}$} & $<1977$ & 22 & 14 & 0 & 36 & 38.80 & 0.00 \\
\hline & $1977-1984$ & 29 & 47 & 45 & 121 & 76.03 & 37.28 \\
\hline & $>1985$ & 7 & 10 & 237 & 254 & 97.24 & 93.30 \\
\hline & Total & 58 & 71 & 282 & 411 & & \\
\hline
\end{tabular}

Table 3 shows that, of the 353 individuals with the registration of having received the measles vaccine, $84(23.80 \%)$ were vaccinated for the first time with the VAS vaccine and 269 (76.20\%) with the MMR vaccine. The formulations of the vaccine with these individuals initiated the vaccination, and their vaccination schedules are significantly associated with the birth cohorts to which they belong $(r=0.720 ; p=0.020)$. Of the 84 individuals who initiated the vacci- nation with the VAS formulation, 10 (11.90\%) were born after 1984. These individuals should not have received the VAS formulation, because the MMR formulation was already available at the time of vaccination. The group of 269 individuals who initiated the vaccination with the MMR, 32 (11.90\%) were born before that date, so they should not have been vaccinated with MMR, but with VAS, because the MMR formulation was not yet available at the date 
of vaccination. The remaining 237 individuals (88.10\%) initiated vaccination with MMR and were born already after 1984 .

The vaccination schedules initiated with MMR1, in individuals born before 1984, may correspond to vaccinations performed after the recommended age, and vaccination schedules initiated with VAS I, in individuals born after 1984 , may correspond to vaccinations performed before the recommended age.

Table 3

Vaccination schedule followed considering the generation of birth from which it was already possible to receive the MMR formulation

\begin{tabular}{|c|c|c|c|c|c|c|c|}
\hline \multirow{2}{*}{ Variables } & \multirow{2}{*}{ Groups } & \multicolumn{4}{|c|}{ Initiated vaccination } & & \\
\hline & & \multicolumn{2}{|c|}{${ }^{\mathrm{a}} \mathrm{VAS}$} & \multicolumn{2}{|c|}{${ }^{\mathrm{b}} \mathrm{MMR}$} & \multicolumn{2}{|r|}{ Total } \\
\hline \multirow{6}{*}{ Birth cohorts } & $\leq 1984$ & \multicolumn{2}{|c|}{74} & \multicolumn{2}{|c|}{32} & \multicolumn{2}{|r|}{106} \\
\hline & $>1984$ & \multicolumn{2}{|c|}{10} & \multicolumn{2}{|c|}{237} & \multicolumn{2}{|r|}{247} \\
\hline & Total & \multicolumn{2}{|c|}{84} & \multicolumn{2}{|c|}{269} & \multicolumn{2}{|r|}{353} \\
\hline & & \multicolumn{4}{|c|}{ Vaccination schedule followed } & & \\
\hline & & \multicolumn{2}{|c|}{ (1 dose) } & \multicolumn{2}{|c|}{ (2 doses) } & & \\
\hline & Variables & $\mathrm{c}_{\text {VAS I }}$ & $\mathrm{d}_{\mathrm{MMR} 1}$ & $\begin{array}{c}\text { VAS I } \\
\mathrm{e}_{\text {VAS II }} \\
\text { gPR I }\end{array}$ & $\begin{array}{c}\text { MMR1 } \\
\mathrm{f}_{\mathrm{MMR} 2}\end{array}$ & Total & $\begin{array}{c}p \\
r\end{array}$ \\
\hline \multirow{4}{*}{$\begin{array}{l}\text { Generation } \\
\text { of birth }\end{array}$} & $<1977$ & 13 & 1 & 0 & 0 & 14 & $0,020^{*}$ \\
\hline & $1977-1984$ & 22 & 25 & 39 & 6 & 92 & $0,720^{* *}$ \\
\hline & $>1984$ & 0 & 10 & 10 & 227 & 247 & \\
\hline & Total & 35 & 36 & 49 & 233 & 353 & \\
\hline
\end{tabular}

Note. ${ }^{\mathrm{a}}$ VAS $=$ Measles vaccine; ${ }^{\mathrm{b} M M R}=$ Measles-mumps-rubella vaccine; cVAS I $=1^{\text {st }}$ dose of measles vaccine; $\mathrm{d}_{\mathrm{MMR} 1}=1^{\text {st }}$ dose of measles-mumps-rubella vaccine; eVAS II $=2^{\text {nd }}$ dose of measles vaccine; $\mathrm{f}_{\mathrm{MMR} 2}=2^{\text {nd }}$ dose of measles-mumps-rubella vaccine; $\mathrm{g}_{\mathrm{PR} I}=1^{\text {st }}$ dose of mumps-rubella vaccine. ${ }^{*} p=$ level of significance of Spearman's correlation coefficient; ${ }^{* *} r=$ Spearman's correlation coefficient.

Of the total of 411 individuals included in the sample, only 73 gave positive responses of the history of measles, the proportion of positive reports being higher in the generation born between 1977-1985 (47/73; 64.38\%). The reports of disease occurrence were also higher in pre-school age and school age $(55 / 73 ; 75.34 \%)$. It should be noted that, of the 73 individuals with positive reports of disease, 43 (63.01\%) had records of taking one or two vaccine doses. No statistically significant differences were found between the reports of the occurrence of disease cases and the vaccination status $(p=0.984)$. Also, there was no statistically significant association between incidence of measles and vaccination status (Phi $=0.044 ; p>0.05$; Table 4). 
Table 4

Reports of positive history of measles by vaccination status, generation of birth, and age of occurrence of the disease



Note. VAS $=$ Measles vaccine. ${ }^{*} p-\chi^{2} .{ }^{* *} P h i V-$ Phi and $V$ with $p>0.05$

The reports of adverse reactions to vaccination were very few. Only 12 individuals reported a positive history of adverse reactions to vaccination, the generation with more reports present- ed being that born between 1977-1984 (six individuals, 50\%) and with only one vaccine dose taken; Table 5).

Table 5

Reports of adverse reactions to vaccination by vaccination status and generation of birth

\begin{tabular}{|c|c|c|c|c|c|c|}
\hline & \multirow{2}{*}{ Birth cohort } & \multicolumn{3}{|c|}{ Vaccination status } & \multirow{2}{*}{ Total } & \multirow{2}{*}{$\begin{array}{c}p \\
P h i V\end{array}$} \\
\hline & & 0 VAS & 1 VAS & 2 VAS & & \\
\hline \multirow{4}{*}{$\begin{array}{l}\text { Reactions to } \\
\text { vaccination }\end{array}$} & Before 1977 & & \multirow{3}{*}{6} & & & \\
\hline & 1977-1984 & & & 2 & 8 & $0.984^{*}$ \\
\hline & $>1985$ & & & 4 & 4 & $0.033^{* *}$ \\
\hline & Total & & 6 & 6 & 12 & \\
\hline
\end{tabular}

Note. VAS $=$ Measles vaccine. ${ }^{*} p-\chi^{2} .{ }^{* *} P h i V-P h i$ and $V$ with $p>0.05$.

\section{Discussion}

Vaccination records are an essential means of proof and documentation of the vaccination history of each individual and an important means of monitoring the NVP implementation, as they contribute to the production of epidemiological indicators for the assessment of a country's vaccination policy (Gonçalves, Frade, et al., 2016; Gonçalves et al., 2015).
In the studied sample, we could compare the vaccination information recorded in the BIS and FIV of 159 individuals (159/411; 38.7\%). Now, the vaccination information recorded in these two documents did not coincide in only 6 individuals $(6 / 159 ; 3.8 \%)$, due to the lack of records of vaccine doses in the FIV, included otherwise in the BIS, and to an error of registration of a vaccination date, which leads to believing that the vaccination information of the sample is quite reliable. 
In this study, the younger generations showed a higher number of vaccine doses taken and also presented vaccination coverage rates above $90 \%$. This evolution of the vaccination coverage rate was similar to that recorded in the region of origin of the sample and also to that recorded in continental Portugal (Cutts et al., 2013; Direção-Geral da Saúde, 2017).

The older generations were vaccinated first with VAS vaccine, and the younger ones already with MMR vaccine, since the latter only became available in Portugal in 1987 (Frade et al., 2017; Direção-Geral da Saúde, 2017). Nevertheless, we found 10 individuals (10/247; 4.05\%) who, though born after 1985 (year of birth after which one could already be vaccinated with MMR), still initiated vaccination with VAS. This may be because (1) these individuals had already completed 15 months of age at the date of vaccination (June 1986), and MMR did not yet exist, so they were still vaccinated with VAS; (2) they were vaccinated before completing 15 months of age and with VAS because MMR was not yet available; (3) they were vaccinated with VAS, although MMR already existed, for reasons unknown. After checking the age at which these individuals took the first dose of measles vaccine, we found that three individuals $(3 / 411 ; 0.7 \%)$ were vaccinated before completing 12 months of age, and 47 (47/411; $11.4 \%$ ) took the first vaccine dose between 12 to 14 months of age (although it was within the 12 months of age, it was before the recommended age of 15 months), which seems to confirm the fact that some individuals still took VAS instead of MMR, even though born after 1984. In contrast, there are 32 individuals born still before 1984, when there was still no MMR (Direção-Geral da Saúde, 2017), who should, thus, have initiated vaccination with VAS, but already took the new MMR vaccine formulation, which appeared only in 1987 (Direção-Geral da Saúde, 2017). This was probably because the vaccine was administered already after the age recommended by the DGS (15 months of age). This vaccination act represents an additional effort to update and increase the vaccination coverage rate, for this group of individuals, since vaccination was performed already after the recommended age. This situation seems to be confirmed when checking the age of the first vaccine dose, corresponding precisely to 32 individuals $(32 / 41 ; 17.8 \%)$, who were vaccinated for the first time against measles with MMR1 vaccine, already after having completed two years of age (Frade et al., 2017).

Of the 282 individuals who received two vaccine doses, $49(49 / 282,17.4 \%)$ initiated vaccination with VAS and completed it with MMR1. The remaining 233 initiated vaccination with MMR1 and completed it with the corresponding MMR2. The first 49 followed the VAS/MMR1 schedule, because they were born more than 15 months before the introduction of MMR in Portugal, that is, before July 1985 . As a result, they initiated vaccination with VAS (Direção-Geral da Saúde, 2017) because MMR still did not exist, and in 1990 , because they had less than 13 years of age (born after 1977), took MMR1, when the second dose of MMR was introduced, which should be administered between 10-13 years of age (Frade et al., 2017).

Among the 233 individuals (233/411; 56.7\%) who initiated vaccination with MMR1 and completed it with MMR2, there are six individuals $(6 / 233 ; 2.6 \%)$ born before 1984 , meaning they should have initiated vaccination with the monovalent vaccine (VAS), but instead did it with the trivalent vaccine (MMR), probably because they were already vaccinated after the 15 months of age. After checking the age of administration of the first vaccine dose, we noted that at least eight individuals, born after 1984, already took the first vaccine dose after the 24 months of age (Direção-Geral da Saúde, 2017; Frade et al., 2017). This fact seems to be because those six individuals were possibly vaccinated with MMR and not VAS.

This analysis proves that the vaccination information of the sample corresponds to what was the vaccination policy for Portugal at the time these individuals were vaccinated, and in the cases in which the vaccination was not precisely the one recommended. This may be an example of nurses seizing an opportunity to update the vaccination of these individuals. In this respect, we considered that the nursing interventions regarding the recording of vaccination information belonging to this sample seem to be entirely accurate and valid, as they correspond precisely to the administered vaccines and their respective dates of administration. 
Some authors emphasize the existence of disease cases in vaccinated individuals, which is not expected. However, the incidence of disease, according to these same authors, is much lower in vaccinated individuals (Gonçalves et al., 2015; Gonçalves, Nunes, et al., 2016). These data may be related to the fact that individuals were vaccinated after the disease incident, which could have happened in vaccination campaigns, where the history of illness of the individual is not taken into account (Gonçalves, Nunes, et al., 2016), or to the possible effect of memory bias. For sure, when these individuals were questioned about the existence of a history of disease, the disease had already occurred a long time ago, thus generating less actual answers, either related to the indicated age for its occurrence or the existence of the disease itself.

It was more incident in pre-school and school age, a fact consistent with the World Health Organization (WHO), which documents that the disease has a higher incidence between 5 and 9 years of age (World Health Organization, 2018). As regards the disease incidence by the generation of birth, we found that measles had the highest incidence in cohorts born between 1976-1985. These individuals would be, at the time, between 3 years old and little more than 10 years old, when there was a measles outbreak in Portugal in 1987, in addition to the small outbreaks every year in the country (European Center for Disease Prevention and Control, 2017).

Only 12 individuals $(12 / 411 ; 2.9 \%)$ had positive reports of adverse reactions to vaccination, which agrees with the literature, that states that the vaccine is very safe and the incidence of adverse reactions is too low (Cutts et al., 2013). We highlight, as the main limitations to this study, the non-probabilistic sampling, thus not representing the Portuguese population, and the MMR vaccination strategy as the sole research object. The possible effect of memory bias, which may be the result of applying the questionnaires on the history of disease and adverse reactions to vaccination, which could already have happened a long time ago, is also a limitation, so the extrapolation of these data for the general population should be made with caution. However, the sample presents characteristics regarding the vaccination history which are very similar to those of the region of origin of the sample and those of continental Portugal. Also, the vaccination coverage rates of the MMR strategy do not differ from the vaccination coverage rates of other vaccination strategies contemplated in the Portuguese NVP.

\section{Conclusion}

The vaccination records carried out by nurses in Portugal can be considered of extreme quality, accurate, reliable, and valid. This quality is due to the coincident information recorded in the BIS and FIV and also because the records of different vaccine formulations correspond to the dates of their implementation in Portugal, and are in compliance with their norms and guidelines. The rate of immunization coverage increased to two vaccine doses, following the different DGS guidelines in their several normative circulars, as a result of the different vaccination strategies that were being applied in Portugal. As the MMR vaccination strategy was applied in Portugal, the vaccination coverage rate increased significantly for both the first and second doses, following the many guidelines introduced in the Portuguese NVP over time.

Individuals born before 1977 performed the VAS I vaccination schedule, those born between 1977-1984 took the VAS I or MMR1 schedule or still the VAS I and MMR1, and those born after 1984 received the MMR1 - MMR2 vaccination scheme.

Generally, the individuals born before 1984 were vaccinated with the VAS vaccine formulation, and the individuals born after this date already took the MMR formulation. Individuals not included in these diagrams either missed opportunities for vaccination or were vaccinated after the recommended age.

The incidence of disease decreased drastically, in particular in the younger generations, because there was not a single endemic measles case in the country since 2004 .

The incidence of adverse reaction reports was also low, which confirms the high safety levels of the vaccine being administered in Portugal for the vaccination strategy in the fight against measles. In addition, these results reflect the success of nursing interventions in three moments: (1) the pre-vaccination that envisages 
determining estimates of vaccination coverage rates, identifying pockets of particularly vulnerable populations, the call for vaccination, the organization and planning of vaccination campaigns, health education for individuals, family, and community, and the maintenance of physical and material conditions necessary for the proper use of vaccines; (2) the vaccination itself that envisages the patient's reception/initial assessment, the identification of contraindications to the vaccine, the demystifying of false contraindications, the information of possible side effects and adverse reactions, the adequate preparation of the vaccine and its proper administration; (3) the moment of post-vaccination that envisages the record of vaccination information in the BIS and FIV (administered vaccine formulation, dose, dose number, batch number, and date of inoculation), information on the date of the next inoculation, action in case of anaphylactic reaction, monitoring of adverse and secondary reactions, assessment of vaccination campaigns.

This study demonstrates the importance of nursing vaccination records in the production of epidemiological monitoring and surveillance indicators of the NVP implementation, which guarantee its success in Portugal.

\section{References}

Cutts, F. T., Lessler, J., \& Metcal, C. J. (2013). Measles elimination progress: Challenges and implication for rubella control. Expert Review of Vaccines, 12(8), 917-932. doi:10.1586/14760584.2013.814847

Direção-Geral da Saúde. (2017). Programa nacional de vacinação: Boletins de vacinação, 1, 6-8, 10, Publicaçôes cientificas. Retrieved from https://www.dgs.pt/ paginas-de-sistema/saude-de-a-a-z/programa-nacional-de-vacinacao/relatorios-e-publicacoes.aspx

European Centre for Disease Prevention and Control. (2011). Surveillance report: European monthly measles monitoring (Vol. 2). Retrieved from http://www.ecdc. europa.eu/en/publications/Publications/2011_July_ Measles_Monthly_Monitoring.pdf

European Centre for Disease Prevention and Control. (2017). Epidemiological update: Measles: Monitoring european outbreaks. Retrieved from https://ecdc.euro- pa.eu/en/news-events/epidemiological-update-measles-monitoring-european-outbreaks-2-june-2017

European Centre for Disease Prevention and Control. (2019). Measles cases on the rise in europe again following drop during summer. Retrieved from www. univadis.co.uk/viewarticle/measles-cases-on-therise-in-europe-again-following-drop-during-summer-650453

Frade, J., Frade M., Henriques C., Silva A., \& Gonçalves G. (2017). Nursing and vaccination, evolution of compliance of measles, mumps \& rubella vaccine. Revista de Enfermagem Referência, 4(13), 9-18. doi:10.120707/RIV17002

George, F., Valente J., Augusto, G. F., Silva A. J., Pereira N., Fernandes T., ... Freitas, G. (2017). Measles outbreak after 12 years without endemic transmission, Euro Surveill, 22(23). doi:10.2807/1560-7917

Gonçalves, G., Frade, J., Nunes, C., Mesquita, J. R., \& Nascimento, M. S. (2015). Persistence of measles antibodies, following changes in the recommended age for the second dose of MMR-vaccine in Portugal. Vaccine, 33(39), 5057-5063. doi:10.1016/j. vaccine.2015.08.057

Gonçalves, G., Frade J., Nascimento, M. S., Mesquita, J. R., \& Nunes, C. (2016). Persistence of rubella and mumps antibodies, following changes in the recommended age for the second dose of MMR vaccine in Portugal. Epidemiology \& Infection, 144(15), 3139-3147. doi:10.1017/S09502688160001655

Gonçalves, G., Nunes, C., Mesquita, J. R., Nascimento, M. S., \& Frade J. (2016). Measles antibodies in cord blood in Portugal: Possible consequences for the recommended age of vaccination. Vaccine, 34(24) 2750-2757. doi:10.1016/j.vaccine.2016.04.007

Loureiro, H. (2004). Efficacy in vaccination: Essential elements in nursing practice. Revista de Enfermagem Referência, 12. Retrieved from https://rr.esenfc.pt/rr/index.php? module $=$ rr\&target $=$ publicationDetails\&pesquisa $=\&$ id_artigo $=2057 \&$ id_revista $=5 \&$ id_edicao $=9$

Subtil, C. L. (2011). The beginnings of the organization of the national vaccination program in Portugal. Revista de Enfermagem Referência, 3(4), 167-174. doi:10.12707/RIII11HM2

Witt, C. L. (2013). Vaccinations: Nursing response and responsibility. Advances in Neonatal Care, 13(2), 83-84. doi:10.1097/ANC.0b013e31828ac848

World Health Organization. (2018). Measles outbreaks: Regions of the Americas, Europe and Africa. Retrieved from http://www.who.int/csr/don/2011_10_07/en/ 
